\title{
Reflection on an Innovative International Partnership during the COVID-19 Pandemic
}

\author{
Ling Gao LeBeau \\ Syracuse University, U.S. \\ Fajun Zhang \\ Southwest University, China
}

\begin{abstract}
This reflective essay discusses how Southwest University (China) created an innovative international partnership initiative with universities in Australia, New Zealand, and the U.S. during the global pandemic. It articulates the context of the initiative, agreement establishment, program implementation, and lessons learned. This reflection aims to provoke deep thinking of how transformative international cooperation could help impact higher education internationalization.
\end{abstract}

Keywords: partnership, internationalization, innovative, higher education

Southwest University (SWU), a public research university in Chongqing, China, thought outside of the box and created an unprecedented international partnership initiative in May 2021 during the pandemic. SWU collaborated with a few Australian universities and one American university to provide an in-person teaching and authentic campus environment for Chinese students who were matriculated to those universities but not able to travel outside of China due to the global pandemic. This unique partnership provides a much-needed opportunity for students to continue with a college education and a creative way to build emergent institutional partnerships and help partner institutions avoid enrollment crash. This essay reflects on this unconventional international cooperation to showcase how an example of a new paradigm of internationalization emerged and 
how a conventional international partnership approach could be transformed during the global challenge to make an impact on student learning.

The unprecedented hit of COVID-19 has caused catastrophic disruption to higher education institutions' financial capacity worldwide. According to the Association of International Educators (NAFSA) survey (2020), the U.S. higher education institutions have lost nearly one billion dollars due to programs and activities associated with international education, such as canceled study abroad programs and funds to support international students and scholars. It is estimated that at least three more billion dollars would be lost in fall 2020 due to the expected decline of international student enrollment and continued withholding of study abroad programs. Many experts in the field of internationalization predict that the financial loss due to the COVID-19 may end internationalization as a tradable commodity, and a new paradigm of internationalization will prevail (de Wit, 2020). While we are all in the dark tunnel seeking light, de Wit and Knight remind us (2018) "As we look backwards and forwards, it is thus important to ask one question. What are the core principles and values underpinning internationalization of higher education that 10 or 20 years from now will make us look back and be proud of the track record and contribution that international higher education has made to the more interdependent world we live in, the next generation of citizens, and the bottom billion people living in poverty on our planet?" (de Wit, 2020).

Prior to the pandemic breakout, one of the critical movements of higher education internationalization was developing and implementing effective and impactful international partnerships. Governments, higher education institutions, and organizations were urging for increased collaborations. Conventionally, international partnerships help universities diversify educational programs and increase research portfolios. The global pandemic spurs some unprecedented international collaborations. According to the American Council on Education (ACE) (n.a.), three decades ago, the landscape of international partnerships among higher education institutions was rather limited, compared to the scope and purposes of partnership models nowadays. In the earlier time, international partnerships focused on "technical assistance", such as student exchange as well as faculty exchange and research collaboration. With internationalization increased in higher education, international partnerships have now been infiltrated in all dimensions of a university (i.e., teaching, learning, research, and service). In addition, partnership guidelines and processes are better established. ACE (n.a.) identifies three primary goals of international partnership: 1) academics and reputation; 2) research and funding: 3) institutional development and service.

With the evolvement of higher education's mission and functions in the society, international collaboration adjusts its model and procedures as well to serve the new strategies and goals of higher education. Joint collaborations among international institutions are: 1) student and faculty mobility; 2) cooperative development and institutional capacity-building projects; 3) collaborative research and training; 4) cooperative and collaborative degrees: collaborative 
teaching; 5) projects involving organizations, businesses, and communities near one or more partners (ACE, n.a.). Without the pandemic, it is quite likely the routine collaborations would sustain and evolve steadily. Nevertheless, the breakout of pandemic forces higher education to change and act quickly even if we were not prepared. Under some circumstances, we broke out established protocols and processes and thought outside of the box to continue to educate students. The damages and challenges of the pandemic to international higher education were evident. Adaptability is one of the top traits that international higher education adopts during the challenging time. It compels higher education to be innovative and creative.

ACE's (2021) findings from the survey with the topic of "Internationalization in the U.S. and U.K. - Present Impacts and Future Implications of COVID-19" states that the U.S. and U.K. leaders list student enrollment as one of the top three priority areas. U.S. and U.K. Both saw a decline in total student enrollment in fall 2020 compared to fall 2019. To avoid enrollment crash, starting late spring of 2020, major countries that host many Chinese students were creating ways to retain newly admitted Chinese students. Because of the covid travel restrictions installed and host country's embassies closed, Chinese students cannot travel abroad to study. They needed to either study fully online or take a leave of absence for fall 2021. Experience of a real campus is crucial for first-year college students. Finding a solution to the urgent learning need became a livelihood issue of great concern to universities outside of China as well the Chinese society.

In Spring 2020, after the pandemic was relatively controlled in China, SWU reached out to partner universities in Australia, New Zealand, and the United States, proposing programs to offer real campus college education to Chinese students who cannot leave the country. SWU's approach aligns with its internationalization goal of expanding cooperation with overseas partner universities and deepening the cooperation and friendship. SWU established a learning center in Spring 2021, named World Renowned University Overseas (Chongqing) Learning Center (OLC), and soon reached cooperation agreements within an unprecedented short timeframe with the University of Western Australia, the University of Technology Sydney, the University of Auckland, and a private research university in the U.S. in Fall 2021.

The OLC provides campus study experience for Chinese students from those universities. OLC students maintain their active student status in their home institutions (Australia, New Zealand, \& the U.S.) and register and pay tuition to home institutions accordingly, while studying at SWU OLC. The students agree to abide by the rules and regulations of SWU. Partner universities were fully in charge of academic plans and registered students for online courses on home campuses. SWU arranged for SWU faculty to deliver one or two in-person courses (pre-approved by home universities) and academic tutoring and support to students. Students took the rest of the courses fully online as their home universities required. Academic supports provided included but were not limited to one-on-one course tutoring, writing consultation, and academic workshops. 
SWU's International Education Center served as the engine that administered the partnership and provided full student services to OLC students, for example, access to school facilities and resources as other SWU students, participating in SWU student associations, and student counseling.

According to the OLC's student survey findings, 88 percent of students who participated in the survey believe that the teaching facilities and learning environment at OLC met or exceeded their expectations. Ninety-two percent students were satisfied or delighted with the room and board at OLC. The frequency of students interacting with OLC academic support staff was comparatively low. Only 61 percent of students took advantage of the resources frequently. Among the students who frequently utilized the academic support resources, 90 percent believed the academic support was helpful or very helpful. What is interesting is that 100 percent of students believe they study very hard for the home university's online courses. Challenges reflected by program administrators and faculty were primarily on student conduct, safety management, and students' lack of integration into the SWU's academic culture. Because OLC served as a temporary campus, some students looked at the learning environment as a "foster home" and did not behave or act as a traditional student, and they lacked interest in knowing more about the host university's culture.

Despite the challenges, the OLC program fulfilled its commitment to international partner universities during the pandemic and has received positive comments from partners. This unprecedented cooperation expands the internationalization horizon for SWU and opens a new arena for the SWU's internationalization plan with innovative opportunities. The successful implementation of the OLC program during such a restricted timeframe proliferated SWU's confidence in introducing and exporting high-quality education resources to partners in the world. It also demonstrates a new way of international partnership to higher education institutions, which does not exist in any partnership literature. We learn from this unconventional cooperation that agility and adaptability are essential to the internationalization of higher education in the evolving and changing world. There are many ways to facilitate student learning and provide the best education to college students if we are open-minded and willing to take proper risks.

The pandemic propels the higher education institutions in the world and other organizations to profoundly reflect on the past one and a half years and address systematic social and educational issues, impacted by the pandemic. We need to review policies and operational models and decide what needs to be changed, and what may be transformed. In terms of international partnership, the SWU case tells us that the economic factor, one of the primary reasons for pre-pandemic partnerships, did not play an essential role. Social outcomes (i.e., continuing college education, reduced stress among students and parents, increased trust between SWU and partner institutions) were achieved through the emergent cooperation, which could sustain the partnership. Sharma (2021) summarizes four post-pandemic higher education keywords: recovery, transformation, innovation, 
and inclusion. It is time for us to reflect and transform. As de Wit (2020) predicts, a new paradigm of internationalization will prevail. We as international educators, let us all think about how international education could continue to contribute to the interdependent world we live in.

\section{REFERENCES}

De Wit, H. (2020). Business Model of Internationalization is Falling Apart. University World News. https://bit.ly/3Jmw1fZ

Gatewood, J., \& Sutton, S. (n.a.). Internationalization in action: International partnerships, part one: definition and dimensions. American Council on Education. https://www.acenet.edu/Documents/IIA-Intl-Partnerships-P1Final.pdf

NAFSA (2020). Survey: Financial Impact of COVID-19 on International Education. https://www.nafsa.org/sites/default/files/media/document/2020financial-impact-survey-summary.pdf

Sharma, Y. (2021). IAUP: Leading universities into a post-pandemic world. University World News. https://bit.ly/34kCYyX

LING GAO LEBEAU (corresponding author), PhD, is Associate Director of International Student Success at Syracuse University. She is a scholar practitioner with years of experiences in teaching, research, and administration. Her IE experiences ranging from teaching, ISSS advising, directing study abroad, developing international partnerships, to leading campus internationalization. LeBeau serves on leadership committees of AIEA and NAFSA and publishes on international higher education. Email: lglebeau@syr.edu

FAJUN ZHANG is the founder of the SWU OLC program. He has years of experience in international education and publication administration. Besides the Director of the Office for International Cooperation and Exchanges at SWU from 2015 to 2020, he was also the Education Consul at the Consulate General of PRC in Vancouver, the Director of the Office for Publication Administration at Sichuan Provincial Government, the Dean of the International College at SWU. He is a current council member of the China Education Association for International Exchange and the Vice President of Chongqing Education Association for International Exchange. He became the President of the SWU Press in January 2021. Email: 564169971@qq.com 
The Journal of International Students is a Gold Open Access publication thanks to the generous institutional sponsorship of Old Dominion University and the publication partnership of Emerson College.

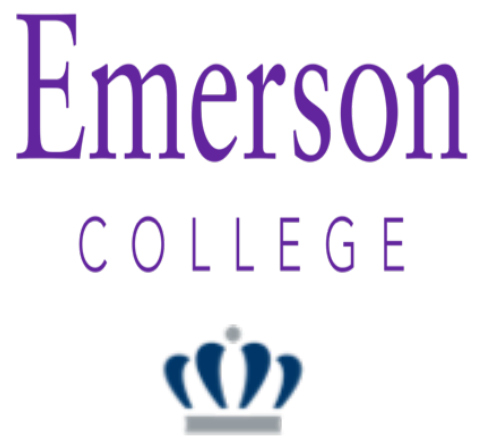

\section{OLD DOMINION \\ U N I V ER S I T Y}

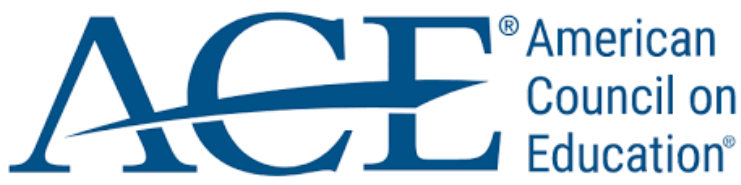

